\title{
The Importance Of Cultural Diversity In The Educational Environment Scale (ICDEE): Development And Testing
}

Douglas Amyx, Louisiana Tech University

Dennis Bristow, (E-mail: dbristow@stcloudstate.edu), St. Cloud State University

\begin{abstract}
College campuses are part of a dynamic and culturally diverse marketplace. As that diversity continues to grow and become an increasingly important component of students = educational environment, university officials need to further their understanding of the students= perspective of cultural diversity on campus. The primary objective in this study was the development and empirical testing of a multiitem paper-and-pencil scale called the Importance of Cultural Diversity in the Educational Environment Scale (ICDEE). Findings showed that the ICDEE demonstrated adequate internal reliability. Implications of the results and administrative applications of the scale in assessment efforts are discussed and avenues for future research are presented.
\end{abstract}

Let us not be blind to our differences B but let us also direct attention to our common interests and the means by which those differences can be resolved. And if we cannot end now our differences, at least we can help make the world safe for diversity B John F. Kennedy, 1963

\section{INTRODUCTION}

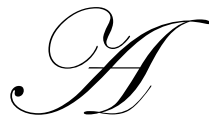

lthough President Kennedy spoke these words some forty years ago, their meaning may be more important today, in the twenty-first century, than at any previous time. Cultural diversity, and our ability and our willingness to acknowledge, understand and embrace it, is perhaps one of the most important components of today $=\mathrm{s}$ rapidly changing world. From college campuses to large and small businesses, from rural to urban settings, the cultural make-up of the United States is rapidly changing and diversity is growing. For example, the U.S. Census Bureau (2001) estimated that in 2005, nearly 33 million blacks, some 12 million Hispanics, 4.3 million Asian American/Pacific Islanders and 2.1 million American Indians will live in this country. Furthermore, by the year 2050 those numbers are predicted to swell to slightly more than 100 million Hispanics, more than 60 million Blacks, slightly more than 33 million Asian/Americans, and 4.5 million American Indians (U.S. Census Bureau 2004a). Such statistics and projections clearly show that the United States is no longer a Acultural melting pot@ but much more closely resembles an Aethnic mosaic $₫$ as suggested by Shim and Gehrt (1996) or AAmerica=s rainbowe as described by Panko and Smith (1997).

The increase in cultural diversity in the U.S. is also reflected on college and university campuses across the nation. Managing cultural diversity in college and university classrooms has become an increasingly important concern (Tompson \& Tompson, 1996). Over the past twenty years, minority enrollments in colleges and universities has mushroomed by over 120 percent, from about two million such students in 1981 to nearly four and one half million in 2001 (American Council on Education, 2003). During the 1990s, Hispanic, Asian, and American Indian enrollments at colleges and universities in the United States increased by more than thirty percent while African American enrollments increased by seventeen percent (Educator=s Reference Desk, 1998). As shown in Table 1, U.S. Government statistics indicate that as of October 2002, over 16 million students, some 5.3 million of minority status, were enrolled at two and/or four year colleges/universities in the United States (U.S. Census Bureau, 2004b). 
The rapid and continued growth in the cultural diversity of student populations across the U.S. and around the globe served as the fundamental motivation for this study. The remainder of this manuscript details a research program designed to develop a tool by which university administrators and other educators can readily assess, from the students= perspective, the importance of cultural diversity on college campuses.

Table 1: Student Enrollment at Four-Year Universities by Race/Ethnic Origin

\begin{tabular}{|c|c|}
\hline Race/Ethnic Origin & Number of Students \\
\hline American Indian & $147,193 *$ \\
\hline Asian/Pacific Islander & $1,200,000$ \\
\hline Black & $2,300,000$ \\
\hline Caucasian & $12,780,000$ \\
\hline Hispanic & $1,660,000$ \\
\hline
\end{tabular}

Source: U.S. Census Bureau, January 9, 2004 Based upon U.S. Department of Education Statistics (2001

\section{The Study}

The research involved the development of a paper-and-pencil assessment instrument designed to measure students= evaluations of the importance of cultural diversity as part of their university learning experiences. The construct of cultural diversity was defined as follows:

Cultural diversity is the representation, in one social system, of people with distinctly different group affiliations of cultural significance (Cox 1994).

Churchill $=\mathrm{s}$ (1979) widely used paradigm for the development of sound multi-item measures was employed in the development of the assessment instrument. The paradigm includes domain specification and item generation, data collection, measure purification, and assessment of the internal reliability of the assessment instrument.

Table 2: Demographic Profile Of Participants

\begin{tabular}{|l|c|c|}
\hline Demographic Variable & Frequency* & Percentage Of Respondents* \\
\hline Age & & $73.1 \%$ \\
$18-21$ & 247 & $21.3 \%$ \\
22 - 25 years & 72 & $2.4 \%$ \\
26 - 29 years & 8 & $2.4 \%$ \\
30 - 35 years & 8 & $.09 \%$ \\
36 years and over & 3 & $47.2 \%$ \\
\hline Gender & & 52.8 \\
Female & 160 & $1.2 \%$ \\
Male & 179 & $5.0 \%$ \\
Race/Ethnic Origin & & $7.7 \%$ \\
American Indian & 4 & $80.8 \%$ \\
Asian/Pacific Islander & 17 & $2.9 \%$ \\
Black & 26 & $2.1 \%$ \\
Caucasian & 274 & $8.3 \%$ \\
Hispanic & 10 & $10.3 \%$ \\
Other & 7 & $56.0 \%$ \\
\hline Year in School & & $24.5 \%$ \\
Freshman & 28 & $.06 \%$ \\
Sophomore & 35 & $19 \%$ \\
Junior & 190 & 23 \\
Senior & 2 & \\
Graduate Student & & \\
\hline
\end{tabular}

* Due to non-response on some items, totals and category responses may differ. 


\section{Participants}

Participants in the study were 339 undergraduate students attending large state universities. Responses to demographic items in the study showed that 160 female and 179 male students participated in the study. Slightly more than eighty percent of the participants (274) were Caucasian. Table 2 presents a more detailed demographic profile of respondents.

\section{Procedure}

In order to generate an initial pool of item statements to be included in the Importance of Cultural Diversity in the Educational Environment Scale (ICDEEE), academicians specializing in the areas of marketing research, consumer behavior, and diversity were consulted and the relevant literatures reviewed. Based upon the suggestions of the academicians and the review of existing scale items, a pool of seven statements was generated. Each of the seven items was reviewed by several other academicians and university students (these reviewers were not otherwise involved in the study) for content validity, clarity, and redundancy. Those reviews resulted in the re-wording of several statements. The revised seven statements were written into a seven-point Likert format with response categories ranging from (1) strongly disagree to (7) strongly agree. To further examine the pool of items for problems in wording, phrasing, or clarity, each statement was reviewed by six outside readers (four undergraduate students and two research assistants) who were asked to examine the items and record any related problems. The readers reported no difficulty in understanding or interpreting the statements. Table 3 presents the initial seven items included in the ICDEE.

Table 3: Importance of Cultural Diversity in the Educational Environment Scale (ICDEE) Items ICDEE Scale Items

1. For me to learn effectively, I must have cultural diversity among students on campus.

2. For me to learn effectively, I must have cultural activities and programs available to me.

3. For me to learn effectively, I must have faculty and staff who are culturally sensitive to me.

4. For me to learn effectively, I must have harmony with students from different cultures.

5. For me to learn effectively, I must have other students who are culturally sensitive to me.

6. For me to learn effectively, I must have a cultural environment that allows me to express myself as an individual.

7. For me to learn effectively, I must have cultural similarity among students on campus.*

* Indicates a reverse scored item

The seven-item ICDEE Scale, along with several demographic questions, was administered to the 339 undergraduate students involved in the study. The data were collected during regularly scheduled classes held at various times of the day and days of the week. All student participants were provided with written and verbal instructions regarding completion of the survey instrument and were informed that their participation in the study was completely voluntary. Further, in order to maintain the anonymity of individual participants, the researchers emphasized that respondents should refrain from putting their names or any other self-identifying marks on the completed survey instrument. Finally, at the conclusion of each data collection period, the primary researchers debriefed the participants and provided a discussion session so that participants could pose questions and/or seek further information or clarification regarding the study.

\section{RESULTS}

Following the recommendations set forth by Churchill, Ford, and Walker (1974), the first step in the evaluation of the psychometric properties of the ICDEE was to examine the internal consistency of the seven items included in the scale. The analysis revealed an overall Cronbach alpha of .854 which, as discussed by Churchill (1979), provides strong evidence that the pool of scale items included in the ICDEE adequately captured the underlying construct. The internal reliability of the ICDEE was further evaluated by examining the correlation of each scale item with the total score. Once again following the lead of Churchill (1979), any scale item with an item-to-total correlation of .25 or less would not be included in further analysis. Analysis of the item-to-total correlations for the seven scale items ranged from a low of .230 
(item \#7) to a high of .784 (item \#5). Accordingly, item \#7 was eliminated from the pool of ICDEE statements and the internal consistency of the remaining six items was reexamined. As shown in Table 4, the six-item ICDEE demonstrated a Cronbach alpha of .885 with item-to-total correlations ranging from a low of .614 (item \#6) to a high of .791 (item \#5).

Table 4: Psychometric Evaluation Of The Importance Of Cultural Diversity In The Educational Environment Scale

\begin{tabular}{|c|c|c|c|c|c|}
\hline $\begin{array}{c}\text { Scale Item } \\
\text { Number }\end{array}$ & $\begin{array}{c}\text { Factor } \\
\text { Loading }\end{array}$ & $\begin{array}{c}\text { Scale Item } \\
\text { Mean }\end{array}$ & $\begin{array}{c}\text { Scale Item } \\
\text { Std. Dev. }\end{array}$ & $\begin{array}{c}\text { Item-to-Total } \\
\text { Correlation }\end{array}$ & $\begin{array}{c}\text { Alpha if } \\
\text { Item Deleted }\end{array}$ \\
\hline 1. & .764 & 3.93 & 1.67 &. .649 & .702 \\
2. & .805 & 3.86 & 1.61 & .731 & .817 \\
3. & .835 & 4.32 & 1.65 & .619 & .812 \\
4. & .762 & 4.89 & 1.56 & .784 & .829 \\
5. & .871 & 4.32 & 1.57 & .625 & .805 \\
6. & .732 & 4.82 & 1.62 & .230 & .828 \\
$* 7$. & .303 & 3.88 & 1.71 & \multicolumn{4}{|c|}{ Overall Cronbach Alpha =.885 } \\
\hline
\end{tabular}

* This item deleted due to low item-to-total correlation

In the second step in the ICDEE analysis, the authors employed common factor analysis to examine the a priori specification of the component structure of the scale. The authors expected that the factor analysis procedure would result in the identification of a single dimension of cultural diversity. A common factors procedure with a varimax rotation and no $n$-factor specified was used to empirically test that expectation. This procedure resulted in the extraction of a single factor. Table 4 shows the final scale structure and factor loadings for the ICDEE.

\section{DISCUSSION AND APPLICATIONS OF THE ICDEE}

The study presented here-in was designed to empirically investigate the psychometric properties of the newly developed Importance of Cultural Diversity in the Educational Environment Scale (ICDEE). The ICDEE was designed to serve as a tool with which college/university administrators can empirically assess, from students= perspectives, the degree to which cultural diversity is an important element of the university learning environment. It also provides a means by which university officials can generate information key to addressing the growing importance of cultural diversity on university campuses and view cultural diversity on campus from the perspective of a key stakeholder B students. The ICDEE could provide insights to student recruitment and retention, curriculum development and/or revision, the allocation of resources, the development of specialized seminars/forums, and more. By utilizing the ICDEE, university administrators can better understand how various segments of the student population perceive the cultural diversity of the institution and make strategic decisions accordingly.

In short, the ICDEE could be used by university researchers, administrators, and other educators as a springboard to further, more detailed student based research. For example, if, in general, student responses to the ICDEE indicated that cultural diversity was an important component of effective learning for students, university officials would be well served to investigate the elements of the educational experience that contribute to such evaluations and grow and nurture related elements or programs. On the other hand, if cultural diversity is deemed relatively unimportant to student learning, university officials might further their understanding of why student perceptions are seemingly in contrast with the reality of the world around them. The ICDEE was designed to be a very versatile, easily adapted instrument with which university administrators can readily assess student perceptions of the institution and compare perceptions across segments of the college/university student population.

The results of this study indicated that the ICDEE is unidimensional and exhibits strong internal reliability (.885). In order to document the usefulness and applicability of the ICDEE to administrators and other educators in higher education, the authors of this manuscript present the details of student responses to the newly developed scale and briefly discuss some of the implications those results might have for administrators at the universities of record. 
The ICDEE consists of six items with response categories ranging from 1 (strongly disagree) to 7 (strongly agree). Accordingly, participant scores on the ICDEE, when summed across all six items in the scale, could range from a low of 6 to a high of 42 , with a possible 35 point spread and a scale midpoint of 24 (an ICDEE score of 24 would indicate respondent neutrality to the importance of cultural diversity in the learning environment). In interpreting respondent scores on the scale, the higher a respondent $=\mathrm{s}$ score, the greater would be that respondent $=\mathrm{s}$ perception that cultural diversity is an important component of the university learning environment. Low ICDEE scores would indicate that a respondent felt cultural diversity was a less important element of the learning environment. Given the possible 35 point spread, a composite score of 23 or less would indicate that students viewed cultural diversity as marginally unimportant to learning. A composite scale score of 25 or higher would indicate student perceptions of cultural diversity as at least somewhat important to learning.

Descriptive statistics revealed that in this study actual respondent composite scores on the ICDEE ranged from a low of 6 to a high of 42, with a mean ICDEE score of 26.1. Those scores indicate that, on average, students at the universities in this study perceived cultural diversity as a minimally important element of the university learning environment. Interestingly, further analysis of student responses revealed that while 112 students (33.5\%) viewed cultural diversity as less important to learning (ICDEE composite score of 23 or less), 202 students (60\%) considered cultural diversity to be at least a somewhat important component of the university learning environment (ICDEE composite score of 25 or higher).

In order to further examine these findings, the authors more closely scrutinized respondents $=$ composite scores on the ICDEE. For example, one might reasonably assign descriptive headings to each of the response categories on the ICDEE. Following this line of reasoning, a response of A2" to a scale item would indicate significant (but not complete) disagreement with that item, while a response of $A 6 "$ to an item would indicate strong (but not complete) agreement with that statement. Accordingly, a composite ICDEE score of 12 (6 scale items times a scale response of 2 to each) would indicate that the respondent viewed cultural diversity as a generally unimportant component of the learning environment. A composite scale score of 36 (6 scale items times a scale response of 6 to each item) would indicate that the student considered cultural diversity relatively important to learning. Further analysis of students $=$ composite scores on the ICDEE revealed that while 31 students $(9.3 \%)$ indicated cultural diversity was generally unimportant to their learning experience (ICDEE composite score of 12 or less), 81 students (24.3\%) indicated that cultural diversity was somewhat unimportant (ICDEE composite score of 13 to 23), and another 147 (44\%) students indicated that cultural diversity was somewhat important to learning (ICDEE composite score of 25 to 35 ). The results also showed that 55 students (16.5\%) indicated strong agreement with the idea that cultural diversity was important to their learning (ICDEE composite score of 36 or higher). Finally, 20 students (6\%) had a composite ICDEE score of 24, indicating that those particular students had an overall neutral attitude regarding their need to have cultural diversity for effective learning. Figure 1 shows a distribution of composite ICDEE scores for the 334 students in the study for whom such scores could be calculated.

Figure 1

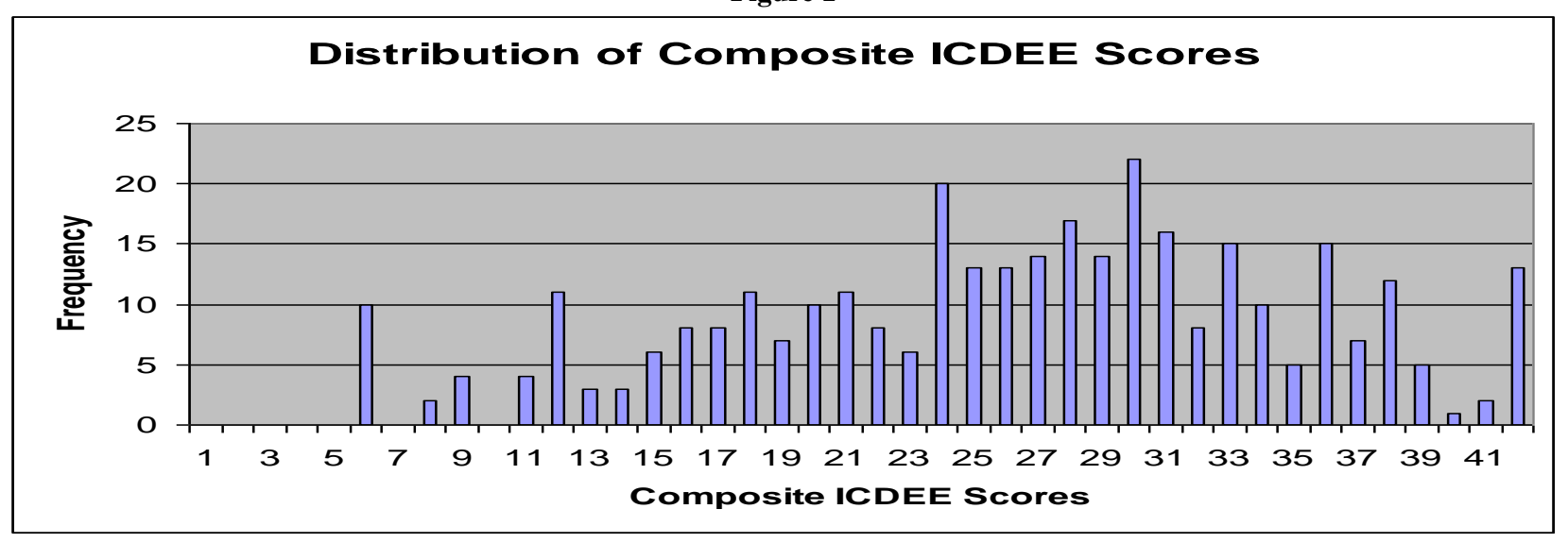


Based upon these findings, administrators and other educators at the universities in question might view the student responses as promising, but with serious concern. While some fifty-six percent of the students in this study indicated that cultural diversity was at least somewhat important to learning, their responses strongly indicate that the university could do much more to communicate the importance of acknowledging, recognizing, and embracing cultural diversity in today $=$ s world.

As a further step in applying the ICDEE to a university $=\mathrm{s}$ understanding of student needs and perceptions, the authors investigated several factors that might be related to student ratings of the importance of cultural diversity as part of the learning environment. The results of that analysis appear in Table 5. First, the authors examined the relationship between the school in which the respondents were enrolled and ICDEE composite scores. It would not be unreasonable to expect students at different universities, located in geographically diverse regions of the United States, to experience distinct cultural environments. For example, at one of the universities of interest (University A), in the three years prior to this study significant resources were devoted to increasing student, faculty, and staff awareness of cultural diversity and related concerns. On-going cultural diversity training seminars were provided and centers for the study of diversity issues were developed as part of a concerted, university wide effort to embrace cultural diversity. While students at the second university in the study (University B) were also encouraged to acknowledge cultural diversity, related efforts and resources dedicated to that end were less robust. Accordingly, the authors expected that students at University AA@ would exhibit significantly higher ICDEE composite scores than would students at University AB.@

Table 5: Level of Importance of Cultural Diversity in the Learning Environment: ANOVA Results

\begin{tabular}{|c|c|c|c|c|c|c|c|}
\hline Independent Variable & Mean & Source & SS & df & MS & $\mathbf{F}$ & $\mathbf{p}<$ \\
\hline $\begin{array}{l}\text { Participant School } \\
\text { A } \\
\text { B }\end{array}$ & $\begin{array}{l}27.76 \\
24.83 \\
\end{array}$ & $\begin{array}{l}\text { Between } \\
\text { Within } \\
\text { Total }\end{array}$ & $\begin{array}{c}711.46 \\
19178.37 \\
19889.83 \\
\end{array}$ & $\begin{array}{c}1 \\
333 \\
334 \\
\end{array}$ & $\begin{array}{c}711.46 \\
57.59\end{array}$ & 12.35 & 0.001 \\
\hline $\begin{array}{l}\text { Participant Gender } \\
\text { Female } \\
\text { Male }\end{array}$ & $\begin{array}{l}26.91 \\
25.43\end{array}$ & $\begin{array}{c}\text { Between } \\
\text { Within } \\
\text { Total }\end{array}$ & $\begin{array}{c}184.44 \\
19756.31 \\
19940.75\end{array}$ & $\begin{array}{c}1 \\
334 \\
335 \\
\end{array}$ & $\begin{array}{c}184.44 \\
59.15\end{array}$ & 3.12 & 0.078 \\
\hline $\begin{array}{l}\text { Participant Ethnicity } \\
\text { Caucasian } \\
\text { Other }\end{array}$ & $\begin{array}{l}24.79 \\
31.73\end{array}$ & $\begin{array}{l}\text { Between } \\
\text { Within } \\
\text { Total }\end{array}$ & $\begin{array}{c}2427.13 \\
17260.85 \\
19687.98\end{array}$ & $\begin{array}{c}1 \\
333 \\
334\end{array}$ & $\begin{array}{c}2427.13 \\
51.83\end{array}$ & 46.83 & 0.001 \\
\hline
\end{tabular}

As shown in Table 5, the analysis revealed that the predicted relationship between the university in which respondents were enrolled and composite ICDEE scores did exist. Students at University AA, $₫$ with a more concerted effort directed at increasing awareness and acceptance of cultural diversity, scored significantly higher $(\mathrm{p}<.001)$ on the ICDEE $(0=27.8)$ than did their counterparts at University $A B @(0=24.8)$. While this finding was statistically significant and as predicted, the results show that in general, students at both schools attach relatively little importance to cultural diversity as part of the learning environment. With this in mind, interested parties at both schools might begin an exploration of students = perceptions of the importance of cultural diversity as a component of the university learning environment. Focus groups might be conducted at both schools as an initial step in determining specific factors related to student ICDEE scores and to aid development of programs designed to increase student perceptions and understanding of the importance of cultural diversity as a part of the academic experience.

In similar fashion, the authors examined differences in mean ICDEE scores by gender of the respondents. Table 5 shows that female respondents tended to score higher on the ICDEE $(0=26.9)$ than did male participants $(0=25.4)$ $(\mathrm{p}<.078)$. These results suggest that at the universities in this study, officials might explore these observed differences and consider the dedication of resources to further their understanding of those differences.

Finally, the authors expected that the ethnic background of respondents might have a significant impact upon the importance attached to cultural diversity as a component of the university learning experience. As shown in Table 2, the 
demographic make-up of the participants in the study was not evenly balanced in terms of ethnic background. Indeed, over eighty percent of the participants were Caucasian with the other twenty percent of the sample consisting of slightly more than 1 percent American Indians, 5\% Asian/Pacific-Islanders, 7.7\% Blacks, about 3\% Hispanics, and 2\% not specified. In order to facilitate investigation of potential ethnic difference in composite ICDEE scores, given the limited numbers of participants in each ethnic category other than Caucasian, the authors aggregated all non-Caucasian respondents into a single ethnic category. The authors emphasize that this compilation was done solely for analytical purposes because of the numerical under-representation of minorities in our sample and does not suggest or assume common experiences, values, beliefs or experiences among the various ethnic groups included in that category. As shown in Table 5, non-Caucasian students deemed cultural diversity to be a more important element of the university learning environment $(0=31.7)$ than did Caucasian students $(0=24.8)(\mathrm{p}<.001)$.

While these findings must be interpreted with caution given the limited ethnic diversity of the participants in this study, the implications for university administrators and other educators and the applicability of the ICDEE are important. More specifically, the ICDEE could be used to provide cross-cultural benchmark assessments of student importance ratings of cultural diversity and if differences are observed in those benchmarks, appropriate strategic decisions could be made to address those differences. For example, Ludlum and Mascaloinov (2004) found that student diversity was an important influence on students= ethical behavior. Similarly, research by Asquith and Bristow (2000) revealed that many students exhibited an ethnic bias regarding perceptions of consumers who are likely to steal. Thus, assessing attitudes about cultural diversity may shed light on strategies for teaching ethics to business students. As such, the ICDEE Scale is designed to be used in numerous pedagogical contexts and should enable educators and administrators to better assess, benchmark, and understand how cultural diversity may affect students= ability and desire to learn; and ultimately, aid in the creation of a more enriching, culturally diverse learning environment.

\section{Limitations And Future Research}

Perhaps the greatest limitation in this study is that the findings are based upon a data collection that reflected the demographic make-up of the student population at two universities B slightly less than $20 \%$ of the participants reported ethnic backgrounds representing minority populations. It would be most interesting to attempt to replicate and extend the results of the study by conducting similar research at several universities/colleges in various regions of the country (or world) with a much more heterogenous and diverse population of students. In addition, the ICDEE was developed so that the instrument might be readily applied, with minor modifications (i.e., changing the name of the university as necessary), across a wide variety of settings and with very diverse student populations. For example, the ICDEE was intended for use by officials at colleges and universities of any size, in urban and/or rural settings, with traditional and/or non-traditional students, and with students representing virtually any culture, ethnic background, or race. The authors strongly encourage researchers to conduct additional empirical work to test the applicability of the ICDEE in such settings.

A second area of concern involves the lack of testing the construct validity of the ICDEE. Accordingly, researchers are encouraged to develop a program of research that would specifically empirically investigate the convergent and discriminant validity of the scale. The MultiTrait-MultiScale matrix developed by Bristow and Mowen (1998) and applied by Bristow, Schneider, and Johnson (in press) and/or structural equation modeling could be used in such future investigations.

\section{REFERENCES}

1. American Council on Education. (2003). Minority college enrollment surges over the past two decades; students of color still lag behind whites in college participation.

2. Asquith, J. L., \& Bristow, D. N. (2000). To catch a thief: A pedagogical study of retail shopping. Journal of Education for Business, 75 (5), 271-276.

3. Bristow, D. N. \& Mowen, J. C. (1998). The consumer resource exchange model: An empirical investigation of construct and predictive validity. Marketing Intelligence and Planning, 16 (6), 375-386.

4. Bristow, D. N., Schneider, K. C., \& Johnson, J. C. (In Press). The Collegiate Student Orientation Scale (CSOS): An empirical investigation of construct validity. Journal of Marketing for Higher Education. 
5. Churchill, G. A., Jr. (1979). A paradigm for developing better measures of marketing constructs. Journal of Marketing Research, 16 (February), 64-73.

6. Churchill, G.A., Jr., Ford, N.M., and Walker, O.C., Jr. (1974). Measuring the Job Satisfaction of Industrial Salesmen. Journal of Marketing Research, 11 (August), 254-260.

7. Cox, T. H., Jr. (1994). Cultural diversity in organizations: Theory, research, and practice. San Francisco: Berrett-Koehler Publishers.

8. Educator=s Reference Desk. (1998). Enrollment Trends at Public Four-Year Colleges and Universities, Fall 1990-1996.

9. Kennedy, John F. (1963). American University, Washington, D.C. 10 June.

10. Ludlum, M. \& Mascaloinov, S. (2004). Right and wrong and cultural diversity: Replication of the 2002 NAS/Zogby Poll on Business Ethics. Journal of Education for Business, 79 (5), 294-298.

11. Panko, R. \& Smith, L. (1997). Selling to America $=$ s rainbow. Best=s Review, 97 (10), 46-51.

12. Shim, S. \& Gehrt, K. (1996). Hispanic and Native American adolescents: An exploratory study of their approach to shopping. Journal of Retailing, 72(3), 307-20.

13. Tompson, H. B. \& Tompson, G. H. (1996). Confronting diversity issues in the classroom with strategies to improve satisfaction and retention of international students. Journal of Education for Business, 72 (1), 53-57.

14. United States Department of Education. (2001). National Center for Education Statistics, Integrated Postsecondary Education Data System, Spring.

15. United States Census Bureau. (2001). Projections of the resident population by race, Hispanic origin and nativity: Middle series, 2001-2005. Populations Projections Program, Population Division.

16. United States Census Bureau. (2004a). Projected population of the United States, by race and Hispanic Origin: 2000-2050. U.S. interim projections by age, sex, race, and Hispanic origin.

17. United States Census Bureau. (2004b). Attendance status of college students 15 years old and over, by age, sex, year and type of college, race, and Hispanic origin: October 2002. 